\title{
Comparative study of some carbonization process parameters of nine eucalypt woods from hajeblayoun arboretum in Tunisia
}

\begin{abstract}
The objective of this work is to study the calorific power of nine eucalypt woods from central Tunisia for carbonization process. The ignition temperature, the calorific power of each species and the gas exhaustion during pyrolysis were measured and their average values were compared. The calorific values of the wood of these species varied between 4017 and $4541 \mathrm{Kcal} / \mathrm{kg}$. The ignition temperature ranged between 252 and $390^{\circ} \mathrm{C}$. The combustion temperature of the samples within the calorimeter was between $463^{\circ} \mathrm{C}$ and $575^{\circ} \mathrm{C}$. The percentage of wood ash after combustion was between 1.0 to $2.2 \%$. The analysis of the experiments conducted during 2 consecutive years showed that certain species were similar while others were significantly different.
\end{abstract}

Keywords: forest species, temperature, eucalyptus, high calorific capacity
Volume 2 Issue 3 - 2017

\author{
Ali Khouaja,' Mohamed Tahar Elaieb, ${ }^{2}$ SA \\ Edgar, ${ }^{3}$ HatemChaar, ${ }^{\prime}$ Amor mlaouhi, ${ }^{2} \mathrm{ML}$ \\ Khouja, ${ }^{2}$ Mathieu Pétrissans ${ }^{3}$ \\ 'INAT, Tunisia \\ ${ }^{2}$ INRGREF,Tunisia \\ ${ }^{3}$ LERMAB, France \\ Correspondence: Mohamed Tahar Elaieb, INRGREF: Rue \\ HédiKarray, BP: № 10 Ariana-2080 Tunisia, \\ Email ayeb2002@yahoo.fr
}

Received: February 23, 2017 | Published: March 20, 2017

\section{Introduction}

According to the International Energy Association the renewable energy from biomass is the most used in the world. It is the cheapest and always available. The biomass is either used directly as wood energy source, compressed as pellets or carbonised to be used as charcoal. It represents a great economic importance on a worldwide scale. Indeed, wood energy (wood and charcoal included) roughly covers $10 \%$ of the energy needs. It provides thus twice more energy than the nuclear power. ${ }^{1}$

As a source of energy, wood accounts for $5.4 \%$ of the total energy used in the world, but with important variations between areas (on average $0.7 \%$ in the industrialized countries and $20 \%$ in the developing countries. ${ }^{2}$ However, the overexploitation of the forests generated an environmental imbalance caused by the cutting of forest trees for industrial and energy uses. Thus, certain human activities and various incomplete combustions, carbonization, forest fires, etc cause discharges of nitrogen oxide, carbon monoxide and other noxious gases to the atmosphere and negatively contribute to climatic warning. ${ }^{3}$ In order to such effects preserve the environment, Tunisia sought the reforestation strategies by mean of using eucalyptus species for energy uses and for its fast growing properties for maximum biomass production in order to meet the local needs. Within this framework, a national strategy of afforestation started since 1988, with the important reforestation objective with an aim of reaching at the year a 2020 rate of national afforestation of $15 \%{ }^{4}$

The range of the species used covers exotic gasolines such as, the acacia and autochtones gasolines like the maritime pine, the stone pine, the Aleppo pine, the cypress and various leafy and resinous gasolines but also the Eucalyptus., ${ }^{5,6}$ Eucalyptus wood species are native to Australia and they were introduced in Tunisia since 50'sby their implantations in bioclimatic arboretums across the country, from centre with a wet climate to the Saharan areas. ${ }^{7,8}$ These fast-growing species were adapted themselves very well to the Tunisian climate. Now, they tend to become invasive wood species which need to be economically valued. The objective of this work is to evaluate the energy performances of nine species of Eucalypti from the arboretum in the central Tunisia under an arid climate. Moreover, one will compare the results obtained during two consecutive years and data can be used to develop wood thermo degradation mathematical model and apply for industries. ${ }^{9-12}$

\section{Material and methods}

\section{Material}

The experimental material concerned nine eucalyptus wood species from the arboretum of Hajeb Layoun :these species were $E u$. Oleosa; Eu. Gilli; Eu. Brevifolia ; Eu. Stricklandii ; Eu.Largiforens ; Eu. Patellaris; Eu. Dumosa;Eu. Salmonophloia et Eu. Brockwayi. Disks were cut from the stem at breast height for the purpose of the study. The calorific power was measured in a calorimeter.

\section{Methods}

The wood samples of each species was extracted and milled into powder to be oven dried. The calorific power of each sample was measured in an adiabatic calorimeter where the ignition temperature was noted.

a. Calorific power (CP): The calorific value was measured using an Automated Isoperibol Fixed Bomb Parr 6200bomb calorimeter, following the CEN/TS $14918,{ }^{13}$ in an atmosphere of $\mathrm{O}_{2}$ that assures the complete combusting of the sample. One oven-dried mass of wood, with particle size $<0.2 \mathrm{~mm}$, are required to perform this test. Two replicates have been done for each wood species.

The 6300 Isoperibol Calorimeter System requires avail-ability of Oxygen, $99.5 \%$ purity, with CGA 540 connection, 2500 psig as maximum. Approximately $2 \mathrm{~L}$ of tap water, with a total hardness of $85 \mathrm{ppm}$ or less, are required for filling the calorimeter jacket reservoir. The inlet pressure was $30 \mathrm{psi}$. The required flow rate is on the order of $0.5 \mathrm{~L} / \mathrm{min}$. The temperature of the water should not exceed $25^{\circ} \mathrm{C}$. 
The Calorimeter automatically makes all the calculations necessary to produce a gross heat of combustion for the sample. Corrected temperature rises reading automatically, and the HHVh was determined, taking into the correction of fuse combustion by the following equation:

$$
\mathrm{HHV}_{\mathrm{h}}=\frac{\mathrm{K}_{1} \mathrm{xE}_{\mathrm{cal}} \mathrm{x}\left(\mathrm{T}_{\mathrm{m}}-\mathrm{T}_{\mathrm{i}}\right)-\mathrm{K}_{1} \mathrm{xLxE_{ \textrm {pt } }}}{\mathrm{M}}
$$

Where HHVh is the Higher Heating Value at constant volume of the fuel as analysed, in $\mathrm{MJ} / \mathrm{Kg}$; $\mathrm{K}$ lis a conversion factor (4.1855 .10$3 \mathrm{KJ} / \mathrm{cal}$; Ecalis a calorimetric equivalent of the Calorimeter apparatus in $\mathrm{Cal} /{ }^{\circ} \mathrm{C}$; $\mathrm{Tm}$ is the maximal temperature in ${ }^{\circ} \mathrm{C}$; Tiis the minimal temperature in ${ }^{\circ} \mathrm{C}$; $\mathrm{L}$ is the burned palatine fuse longer in $\mathrm{cm}$; Ept is the Higher Heating Value at constant volume of the palatine, in MJ/ $\mathrm{Kg}(=2.3 \mathrm{cal} / \mathrm{cm})$ and $\mathrm{M}$ is the mass of the sample in $\mathrm{g}$.

Precise temperature measurements are made with Thermistors thermometry providing $0.0001{ }^{\circ} \mathrm{C}$ resolution over the operating range of the calorimeter. This system differs from adiabatic operation in which the jacket temperature must be adjusted continuously to match the bucket temperature in an attempt to maintain a zero temperature differential with no heat leaks between the bucket and its surroundings. Higher Heating Value in dry basis calculated by the equation according to CEN/TS $14918:^{13}$

$$
\mathrm{HHV}_{0}=\mathrm{HHV}_{\mathrm{h}} \mathrm{x} \frac{100}{100-\mathrm{M}_{\mathrm{ad}}}
$$

Where HHV0 is the Higher Heating Value at constant volume of the dry (moisture-free) fuel, in $\mathrm{MJ} / \mathrm{Kg}$; Mad is the moisture in the analysis sample, in \% by mass; HHVh is the Higher Heating Value at constant volume of the fuel as analysed, in $\mathrm{MJ} / \mathrm{Kg}$.

The Low Heating Value can be determined at constant pressure or at constant volume. The Low Heating Value at constant pressure is however the generally used, since it is the one that is usually used in combustion. His determination is fundamental at the time of evaluating a substance and also gives an idea of the potential to generate and propagate fires. The Low Heating Value at constant pressure for a dry sample is derived from the corresponding Higher Heating Value according to equation in CEN/TS 14918:13

$$
\operatorname{LHV}_{0}(\%)=\mathrm{HHV}_{\mathrm{h}}-0.212 \times \mathrm{xw}(\mathrm{H})_{\mathrm{d}}
$$

Where: LHV0 is the Low Heating Value in dry basis at constant pressure in $\mathrm{MJ} / \mathrm{kg}$; HHV0 the Higher Heating Value in dry basis in $\mathrm{MJ} /$ $\mathrm{Kg}$; w $(\mathrm{H}) \mathrm{d}$ is the hydrogen content, in \% by mass, of the moisturefree (dry). Remark: $(\mathrm{H}),(\mathrm{O}),(\mathrm{N})$ contents (\% dry basis) are the value determined in the elemental composition analysis.

Low Heating Value (as received) calculated according to CEN/TS 14918: ${ }^{13}$

$$
\operatorname{LHV}_{\mathrm{h}}(\%)=\operatorname{LHV}_{0} \mathrm{x} \frac{100-\mathrm{M}_{\mathrm{ar}}}{100}-0.02443 \times \mathrm{M}_{\mathrm{AR}}
$$

Where: LHVh is the Low Heating Value (at constant pressure) as received $(\mathrm{MJ} / \mathrm{Kg})$; LHV0 is the Low Heating Value (at constant pressure) in dry basis ( $\mathrm{MJ} / \mathrm{kg})$; Mar is the moisture content as received $[\mathrm{w} \%] ; 0.02443$ is the correction factor of the enthalpy of vaporization (constant pressure) for water (moisture) at $25^{\circ} \mathrm{C}[\mathrm{MJ} / \mathrm{kg}$ per $1 \mathrm{w} \%$ of moisture].

b. Temperature measurements: The measurement of inflammation and heart temperatures was monitored instantaneously by the mean of a digital probe allowing the measurement from- 33 to $1700 \pm 0.01^{\circ} \mathrm{C}$.

c. Gas measurements: A sample weighting $3 \mathrm{~kg}$ is submitted to the combustion. Gas concentration is measured during the combustion every $10 \mathrm{mn}$ until obtaining the maximum rate of gas exhausted $\left(\mathrm{CO}\right.$ and $\left.\mathrm{CO}_{2}\right)$.

d. Ash content determination: Power Activated Carbon (PAC) of the biomass materials was determined in accordance with ASTM Standard D 1762-84. ${ }^{14}$ This was done by heating approximately $2 \mathrm{~g}$ of the oven-dried mass of each biomass material with particle size of $5425 \mu \mathrm{m}$, in an electric furnace at a temperature of $600^{\circ} \mathrm{C}$ for four hours. Thereafter, it was cooled in a desiccator and weighted to represent the ash content of the sample. The percentage ash content was calculated as follows:

$$
\text { Ash content }(\%)=100 \times \frac{M_{\text {ash }}}{M_{\text {oven-dried }}}
$$

Where Mash is the mass of the ash (g) and oven-dry is the mass of oven-dried sample (g).

\section{Result and discussion}

\section{Calorific values}

Figure 1 shows the values of the higher calorific value obtained for the different eucalyptus species. The examination of the high calorific capacity of the wood species shows that is ranged from $4017 \mathrm{kcal} / \mathrm{kg}$ and $4541 \mathrm{kcal} / \mathrm{kg}$ with a maximum observed at Eucalyptus Stricklandii and a minimum observed at Eucalyptus patellaris. Figure 2 illustrates the values of the temperature of ignition and that of the hearth of the species of eucalyptus. The temperature of wood ignition of these species lies between a maximum observed for Eucalyptus Brockwayi $\left(390^{\circ} \mathrm{C}\right)$ and one minimum observed for Eucalyptus largiforens $\left(292^{\circ} \mathrm{C}\right)$. Moreover the figure shows the variation in temperature of the hearth. It has a maximum value observed at Eucalyptus brockwayi $\left(575^{\circ} \mathrm{C}\right)$ and a minimal value observed at Eu. gillii $\left(463^{\circ} \mathrm{C}\right)$.

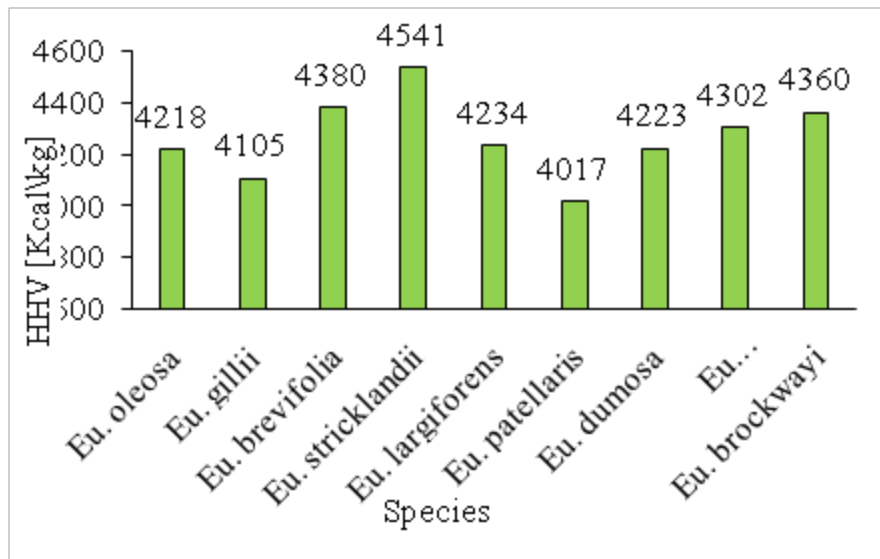

Figure I Higher Calorific Capacity means of the species of Eucalyptus of Arboretum Hajeb Laayoun. 


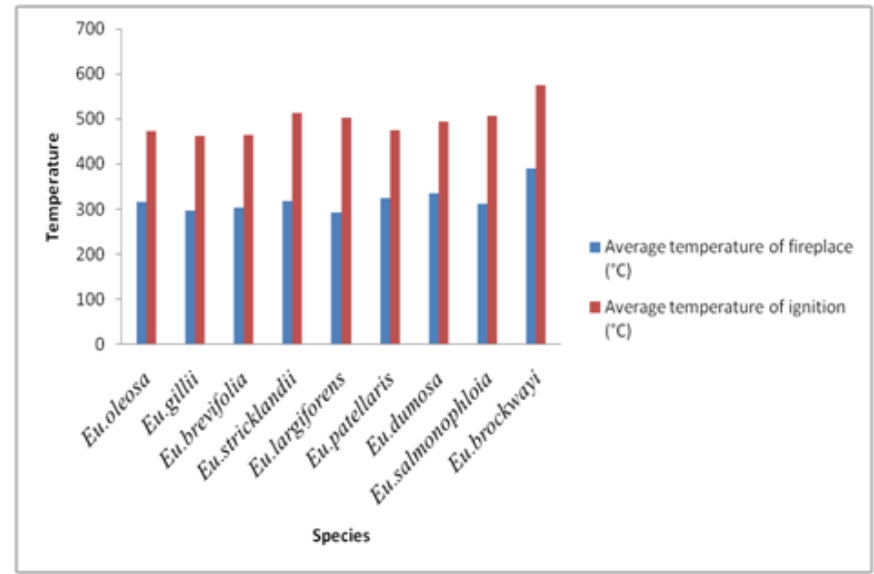

Figure 2 Ignition and the hearth temperatures of some species of Eucalyptus of Arboretum Hajeb Laayoun.

\section{Ash content}

Ash is formed from mineral matter during combustion and gasification. The ash yield of wood grown in the temperate zones is $0.1-1.0 \%$, whereas wood grown in the tropics contains up to $5 \%$ ash. ${ }^{15}$ The bark contains $3-8 \%$, ash. Wood ash typically includes $40-70 \%$ calcium oxide and $10-30 \%$ potassium oxide. ${ }^{16}$ The mineral content of wood and bark is highly variable between and within species and can vary with soil and growth rate.${ }^{17}$ Figure 3 illustrates the percentage of ash resulting from combustion. Indeed, this percentage of ash is ranged from a maximum observed at Eucalyptus patellaris (2.25\%) and a minimum determined at Eucalyptus demise (1.05\%). This interspecies variation of Ash content could be explained by the fact of hardwoods species (Eucalyptus) have a complex anatomical structure which is better able to keep a lot of mineral compounds during its growing than softwood species.

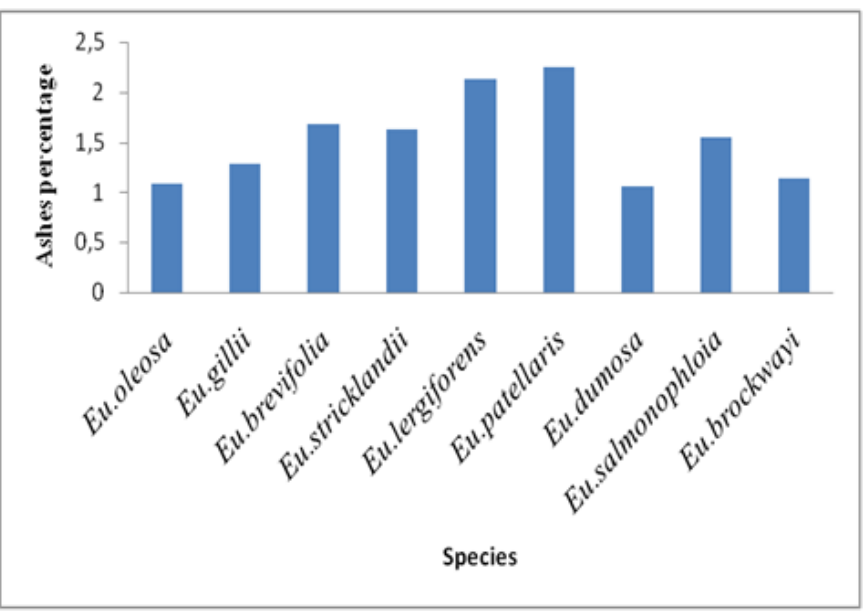

Figure 3 Percentage of ashes of the wood of some species of Eucalyptus of Arboretum Hajeb Laayoun.

\section{Gas measurements}

For the gas exhaust Figure 4 shows that the complete combustion of the wood of different species exhausts almost similar $\mathrm{CO}$ and $\mathrm{CO}_{2}$ percentantages. The $\mathrm{CO}_{2}$ exhausted was maximum or Eu. dumosa $(15.5 \%)$ and Eu. Patellosa (11.5\%) while the values of the CO exhausted were almost the same.

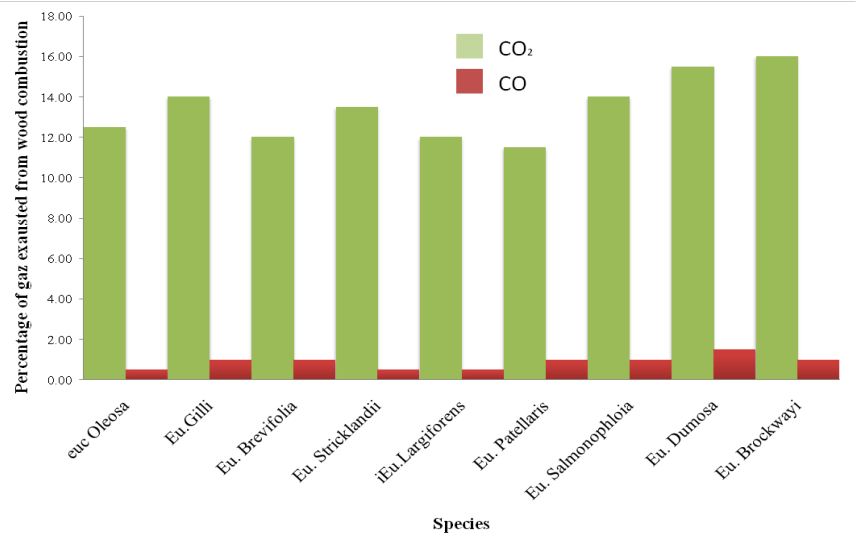

Figure 4 Percent of $\mathrm{CO}_{2}$ and $\mathrm{CO}$ gas exhausted from complete wood combustion.

\section{Conclusion}

Based on this study on the determination of the energy characteristics of 19 forest species, we can conclude that these species constitute a source of energy. The important obtained results show that the wood of these species has a high calorific value which is considerable and variable according to the species and the tree. This high calorific value lies between $4017 \mathrm{kcal} / \mathrm{kg}$ and $4541 \mathrm{kcal} / \mathrm{kg}$, respectively for Eucalyptus patellaris and Eucalyptus Stricklandii. The highest temperature of the ignition was recorded for Eucalyptus brockwayi $\left(390^{\circ} \mathrm{C}\right)$ while the lowed for Eucalyptus largiforens (bicolor), $\left(292^{\circ} \mathrm{C}\right)$. A simple classification of the studied species based on the temperature of the hearth, puts the Eucalyptus brockwayiat the top with a value of $575^{\circ} \mathrm{C}$ and Eucalyptus gillii at the bottom with a value of $463^{\circ} \mathrm{C}$. The percentage of ash reached its maximum level with Eucalyptus patellaris with a value of $2.28 \%$ and its minimum for Eucalyptus dumosa (1.53\%).

\section{Acknowledgements}

None.

\section{Conflict of interest}

The author declares no conflict of interest.

\section{References}

1. Seigue A. It circum-Mediterranean forest and its problems. France: Éditions Maisonneuve et Larose; 1985. 502 p.

2. Lacaux JP, Cachier H, Dalmas C. The ecological, atmospheric, and climatic importance of vegetation fires. In: PJ Crutzen, Goldammer, editors. USA: John Wiley and Ltd Sounds; 1993. 343 p.

3. Dusser P. Study of the boilers with wood: Contribution to the measurement of the emissions of the un burnt compounds, to the rise in the energetic efficiencies and the modelling of combustion. France: Thesis, INSA Lyon; 1986.

4. Marouan. Environmental valorization energy and of some forest and arboricolous species, End-of-study dissertation. Tunisia: ISP Tabarka; 2002.

5. Rezgui M. Rural evaluation energy of fuel in medium in Tunisia. Endof-study dissertation. Tunisia: ISP Tabarka; 2003.

6. Amor J. Possibility of valorization energy of the forest by-products. End-of-study dissertation. Tunisia: ISP Tabarka; 2004. 
7. Khouja ML, Khaldi A, Rejeb MN. Procedings of international conference on Eucalyptus in the Mediterranean Basin: Prospective and new utilization. Italy: Centro Propozione Pubblicita; 2001.

8. Dia A, Duponnois R. Le Projet Majeur Africain de la Grande Muraille Verte: Concepts et Mise en Euvre. IRD; 2010. 440 p.

9. Pétrissans J, Hamada M, Chaouch F, et al. Variations in the natural density of European oak wood affect thermal degradation during thermal modification. Journal of Chemical Information and Modelling. 2014;53:160.

10. Pétrissans R, Younsi M, Chaouch P, et al. Experimental and numerical analysis of wood thermo degradation. Journal of Thermal Analysis and Calorimetry. 2012;19(2):907-914.

11. Rousset P, Turner I, Donnot A, et al. Strength properties of thermally modified softwoods and its relation to polymeric structural wood constituents. Ann for Sci. 2006;63:213-229.
12. Ssafin R, Barcík S, Shaikhutdinova A, et al. Acta facultatis xylologiae zvolen. 2015;57:39-47.

13. CEN/TS 14918. Solid bio fuels-method for the determination of calorific value. 2005:37.

14. ASTM. Standard D 1762-84, Standard test method for chemical analysis of wood charcoal. USA: ASTM International; 2007.

15. Fengel D, Wegener G. Wood: Chemistry. Ultra-structure and Reactions. 1984:613.

16. Ragland KW, Aerts DJ, Baker AJ. Properties of wood for combustion analysis. Bioresource Technology. 1991;37(2):161-168.

17. Elaieb MT, Khouaja A, Valette J, et al. Comparative Study of Local Tunisian Woods Properties and the Respective Qualities of Their Charcoals Produced by a New Industrial Eco-Friendly Carbonization Process. Waste Biomass Valorization. 2016:1-13. 